\title{
Relationship between increased relative birthweight and infections during pregnancy in children with a high-risk diabetes HLA genotype
}

\author{
H. E. Larsson • K. Lynch • B. Lernmark • \\ G. Hansson • Å. Lernmark • S.-A. Ivarsson • \\ DiPiS Study group
}

Received: 26 November 2006 / Accepted: 7 February 2007 / Published online: 4 April 2007

(C) Springer-Verlag 2007

\begin{abstract}
Aims/hypothesis Children with high-risk type 1 diabetes HLA genotype have increased risk of high relative birthweight (HrBW), while cord blood islet autoantibodies decrease the risk. As gestational infections may affect offspring type 1 diabetes risk, the aims were to test whether: (1) children of mothers reporting gestational infections have increased HrBW; (2) gestational infections explain islet autoantibody reduction of $\mathrm{HrBW}$; and (3) gestational infections affect the association between HLA and HrBW.

Subjects and methods HLA genotypes and autoantibodies to glutamic acid decarboxylase, insulinoma-associated protein 2 and insulin were determined in cord blood of children born to non-diabetic mothers in the Diabetes Prediction in Skåne (DiPiS) study. Mothers reported gestational infections when the child was 2 months old.

Results Fever or gastroenteritis during pregnancy was reported by $2,848 / 19,756$ mothers (14\%); 339 in more than
\end{abstract}

Electronic supplementary material The online version of this article (doi:10.1007/s00125-007-0648-6) contains supplementary material, which is available to authorised users.

Members of the DiPiS Study Group are listed in the Acknowledgements

H. E. Larsson · K. Lynch · B. Lernmark · G. Hansson •

Å. Lernmark $\cdot$ S.-A. Ivarsson

Department of Clinical Sciences, University Hospital MAS,

Lund University,

Malmö, Sweden

H. E. Larsson $(\square)$

Department of Clinical Sciences in Malmö-Pediatrics,

University Hospital MAS,

20502 Malmö, Sweden

e-mail: helena.larsson@med.lu.se one trimester. Children whose mothers reported infections had increased risk of HrBW ( $p=0.0003)$, particularly in the absence of cord blood islet autoantibodies (interaction between $\mathrm{HrBW}$, islet autoantibodies and infections, $p=$ 0.0005). The effect on HrBW by high-risk $H L A-D Q 2 / 8$ was aggravated by infections in more than one trimester (odds ratio $[\mathrm{OR}]=5.24 ; p=0.003$ ) (interaction; $p=0.022$ ). When infections were reported, cord blood islet autoantibodies decreased HrBW $(\mathrm{OR}=0.34 ; p=0.0002)$.

Conclusions/interpretation This study revealed that: (1) gestational fever, gastroenteritis, or both, increased the risk of HrBW; (2) cord blood islet autoantibodies decreased the risk of HrBW only in combination with infections; and (3) infections aggravated the association between $H L A-D Q 2 / 8$ and HrBW. These data suggest an interaction between HLA, gestational infections, islet autoantibodies and fetal growth.

Keywords Birthweight - Fever - GAD65 autoantibodies . Gastroenteritis · Gestational infections · HLA

IA-2 autoantibodies · Infections · Insulin autoantibodies .

Islet autoantibodies · Type 1 diabetes

$\begin{array}{ll}\text { Abbreviations } \\ \text { BW } & \begin{array}{l}\text { birthweight } \\ \text { dried blood spot }\end{array} \\ \text { DiPiS } & \begin{array}{l}\text { Diabetes Prediction in Skåne } \\ \text { autoantibodies to glutamic acid } \\ \text { GAD65 Aecarboxylase }\end{array} \\ \text { HrBW } & \begin{array}{l}\text { high relative birthweight } \\ \text { insulin autoantibodies } \\ \text { IAA }\end{array} \\ \text { IA-2Ab } & \begin{array}{l}\text { autoantibodies to insulinoma-associated } \\ \text { protein 2 }\end{array} \\ \text { low relative birthweight }\end{array}$


OR odds ratio

rBW relative birthweight

\section{Introduction}

Type 1 diabetes is a chronic autoimmune disease associated with destruction of the pancreatic islet beta cells, resulting in loss of insulin production. The incidence of type 1 diabetes before 18 years of age is increasing $[1,2]$, and children tend to be diagnosed at an early age [2-5]. HLA genes are strong susceptibility factors for type 1 diabetes [6] but twin studies suggest that environmental factors are also of importance $[7,8]$. The low frequency of first-degree relatives $(10-15 \%)$ with diabetes among children newly diagnosed with type 1 diabetes further supports the importance of environmental factors. High birthweight (BW) has been reported as a risk factor for type 1 diabetes [9-11], in contrast to low BW for gestational age (small for gestational age), which is a risk factor for type 2 diabetes $[12,13]$. Among environmental factors, viral infections have frequently been proposed as triggers of the autoimmune reaction resulting in type 1 diabetes. In several studies, it was shown that children who developed type 1 diabetes were more often born to mothers with Coxsackie or echovirus infections compared with control children [1416], although this could not be confirmed in another study [17]. Children with congenital rubella have been reported to have a high frequency of diabetes later in life [18, 19]. Infections with Coxsackie B virus were reported to occur at an increased frequency in children with newly diagnosed type 1 diabetes compared with control children [20-22], but convincing evidence for or against an association between Coxsackie $\mathrm{B}$ virus infection and type 1 diabetes has not been provided [23].

The autoimmune process destroying the beta cells is marked by autoantibodies to glutamic acid decarboxylase (GAD65Ab) [24], insulinoma-associated protein 2 (IA$2 \mathrm{Ab}$ ) $[25,26]$ or insulin (IAA) [27]. Up to $90 \%$ of children with newly diagnosed type 1 diabetes have at least one of these antibodies. In children born to non-diabetic mothers, autoantibodies in cord blood have retrospectively been found in some children who later developed type 1 diabetes [28]. In contrast, a recent study of children born to mothers with type 1 diabetes reported that GAD65Ab and IA-2Ab in cord blood reduced the risk of developing multiple autoantibodies, diabetes, or both, later in childhood [29].

Recently we reported that children with HLA conferring a risk of type 1 diabetes had an increased frequency of a high relative $\mathrm{BW}$ (rBW: BW corrected for gestational age) [30], suggesting that this high relative $\mathrm{BW}(\mathrm{HrBW})$ as a possible risk factor for type 1 diabetes may be affected by
HLA. In our study, children born to mothers with diabetes were excluded [30]. It is of interest therefore that an association between HLA and BW was also reported in children born to mothers or fathers with type 1 diabetes [31]. We speculated that this effect by HLA on intrauterine growth might also be influenced or mediated by other reported risk factors for type 1 diabetes. For example, we also reported that $\mathrm{rBW}$ was reduced in children born to non-diabetic mothers with GAD65Ab [30]. Since both islet autoantibodies [28] and gestational infections $[15,16]$ have been proposed as risk factors for type 1 diabetes, the aim of the present study was to test the following hypotheses: (1) children born to mothers reporting gestational infections have an increased risk of HrBW; (2) gestational infections explain that islet autoantibodies are reducing the risk of HrBW; and finally (3) that gestational infections affect the association between HLA and HrBW. The hypotheses were tested in an extended cohort (19,756 children) of the previously described Diabetes Prediction in Skåne (DiPiS) study $[30,32]$.

\section{Subjects and methods}

Population The children in this study participated in DiPiS, a prospective population-based study in Skåne, the most southern province of Sweden with 1.2 million inhabitants $[30,32,33]$. The aim of DiPiS is to determine the positive predictive value for type 1 diabetes of genetic risk combined with islet cell autoantibody markers and to identify factors during and after pregnancy that may trigger type 1 diabetes.

Cord blood was genotyped for HLA and analysed for GAD65Ab, IA-2Ab and IAA. The parents filled out the consent form and a questionnaire (partly described in Electronic supplementary material [ESM]) when the child was 2 months of age. Apart from family history of diabetes, BW and gestational age, the questionnaire allowed the mothers to report infections during pregnancy. There were two questions on infections including infectious diarrhoea, vomiting and febrile illness (above $38^{\circ} \mathrm{C}$ ), frequency of illness and during which trimester (see ESM). The Lund University Ethics Committee approved the DiPiS study.

Study group Children included in the DiPiS study between September 2000 and August 2004 were analysed. During this period, 48,058 children were born in the province of Skåne (Fig. 1) and 35,683 cord blood samples were obtained at the five maternity clinics in Malmö, Lund, Helsingborg, Kristianstad and Ystad. After excluding twins, triplets, preterm children (born before 37 weeks of gestation) and children born to mothers with diabetes, 31,446 children remained. BW, gestational age and HLA were available from 19,756 children. A limited 


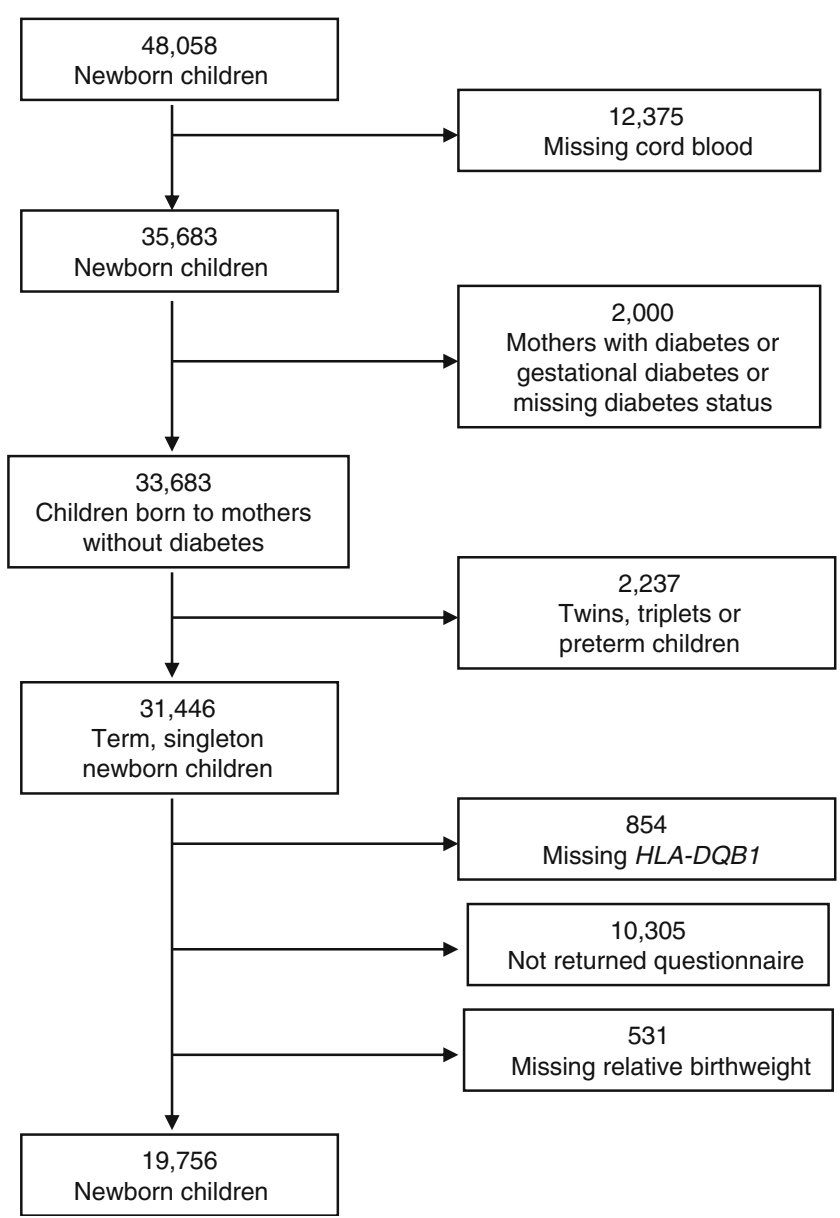

Fig. 1 Children born in Skåne between September 2000 and August 2004, and their participation in DiPiS. Children born preterm, to mothers with diabetes or gestational diabetes, and twins or triplets were excluded

number of mothers had more than one delivery within the inclusion period of the study. The study design precluded an identification of these siblings. We compared participating with non-participating children, to reveal that participation was higher with increasing age of the mother and with increasing gestational age of the child (ESM Table 1). The participation was also slightly higher when the child had high-risk diabetes HLA genotype, but there was no difference if the child had islet autoantibodies in the cord blood or not (ESM Table 1).

HLA genotyping HLA haplotypes were determined as previously described $[30,34,35]$. Briefly, cord blood was dropped onto Whatman filters to generate dried blood spots (DBS). The DBS was used to obtain 3-mm punches, which were used directly for PCR amplification of DQA1 and $D Q B 1$ alleles as described [30]. Single-stranded DNA was hybridised with two sets of probes, the first containing Eu$D Q B 1^{*} 0602 / 3, \mathrm{Sm}-D Q B 1 * 0603 / 4$ and Tb-Control and the second containing Eu-DQB1*0302, Sm-DQB1*0301 and Tb- $D Q B 1^{*} 02$. Samples positive for $D Q B 1^{*} 02$ were further analysed for $D Q A 1^{*} 0201$ and 05 alleles to separate subjects with DR3 from DR7. HLA-DQA1 typing was performed with the same technique as for $D Q B 1$ typing with some modifications as described [30] with use of Sm-DQA1*05 and $\mathrm{Tb}-D Q A 1^{*} 0201$ probes.

The HLA genotypes were divided into seven risk groups for type 1 diabetes: (1) very high risk, having $D Q B 1^{*} 0201$ $A 1^{*} 0501$ and $D Q B 1^{*} 0302-A 1^{*} 0301$ (DQ2/8) $(n=746)$; (2) high risk, having $D Q B 1^{*} 0302-A 1 * 0301$ (DQ8) but not $D Q B 1 * 0201-A 1 * 0501$ (DQ2) $(n=1,860)$; (3) moderate risk, having $D Q B 1 * 0201-D Q A 1 * 0501$ (DQ2) but not $D Q B 1^{*} 0302-A 1^{*} 0301$ (DQ8) $(n=1,682)$; (4) neutral HLA $(n=5,188)$; (5) low-risk HLA $(n=2,373)$; $(6)$ very-low-risk $(n=3,087)$; and (7) no-risk HLA $(n=4,820)$, as described previously [30].

Autoantibodies to GAD65, IA-2 and insulin Autoantibodies to GAD65 and IA-2 were determined in DBSs as previously described $[30,36]$. In brief, DBS eluates were incubated with labelled antigen and immune complexes precipitated using Protein A-Sepharose. The radioactivity in the precipitate was measured and positive samples (combined GAD65 Ab and IA-2Ab analysis $>95$ th percentile) were re-analysed for GAD65Ab and IA-2Ab in separate assays [37, 38]. IAA were analysed with a recently described microassay, which was adapted for a microtitre plate format [39].

Statistical methods and dataset All questionnaires and forms from the DiPiS-study were scanned into a database, BC/OS system, Biocomputing OS 2000 (Biocomputing Platforms Ltd Oy, Espoo, Finland). In term newborns, rBW was calculated as previously described [30]. Briefly, $z$ scores for each gestational week and sex was calculated by the following formula: $z$ score $=(\mathrm{BW}-$ mean $[\mathrm{BW}]) / \mathrm{SD}$ $[\mathrm{BW}]$ and termed as $\mathrm{rBW}$.

Population means (SD) of BW were estimated internally using the study group and relative BW was divided into quartiles. Children in the lower quartile were defined as having a low rBW (LrBW) and children in the upper quartile had HrBW. Differences in proportions were tested using chi-square tests. The linear association of HrBW with number of infections within HLA risk groups was tested using a $\chi^{2}$ test for trend. Interactions between cord blood autoantibodies and infections on the risk of HrBW were tested using logistic regression models. Logistic regression models also were used to examine whether HLA and cord blood autoantibodies were independently associated with HrBW after adjusting for other confounding factors such as sex, gestational age, jaundice, presence of siblings, health of the newborn, presence of jaundice, smoking during pregnancy, maternal age, education of the mother, mother working during pregnancy, lengthy or serious disease in the 
mother over the previous 5 years and maternal weight gain. $p$ values less than 0.05 were considered significant.

\section{Results}

Are infections during pregnancy related to $B W$ ? Of the 19,756 mothers answering the questionnaire, $14.4 \%$ reported fever, gastroenteritis or both (diarrhoea, vomiting or both) during pregnancy (ESM Table 2). Fever was more frequently reported $(10.7 \%)$ than gastroenteritis $(7.7 \%)$, while $3.0 \%$ of the mothers reported both in the same trimester. In total, $1.7 \%$ of the 19,756 mothers reported fever, gastroenteritis, or both, in more than one trimester (ESM Table 2). The mothers tended to report more infections if they were older (>30 years), better educated, had a previous child or reported a serious or lengthy disease in the last 5 years (Table 1). There was also a weak association between smoking and fewer reported infections, but this was entirely explained by lower education in smoking mothers. Cord blood autoantibodies were not associated with the number of infections reported. However, infections were associated with increased risk of $\mathrm{HrBW}(p=0.0003)$ (Table 1). There was no difference in odds ratio (OR) between the effect of fever $(\mathrm{OR}=1.17$ [95\% CI 1.06-1.30], $p=0.002)$ or gastroenteritis $(\mathrm{OR}=1.13 \quad[95 \%$ CI $0.99-1.28], p=0.07)$ on HrBW, but the frequency of infections was of importance (Table 1). When examining the results separately by each trimester, HrBW was associated with infections in the first trimester $(\mathrm{OR}=1.22[95 \% \mathrm{CI} 1.06-1.40], p=0.005)$ and second trimester $(\mathrm{OR}=1.21$ [95\% CI 1.06-1.38], $p=0.006)$ but not with infections during the third trimester $(\mathrm{OR}=1.11$ [95\% CI 0.97-1.28], $p=0.14$ ).

Are autoantibodies and infections related to $r B W$ ? Among all newborns, cord blood GAD65Ab was associated with decreased risk of $\mathrm{HrBW}(\mathrm{OR}=0.82$ [95\% CI 0.67-0.99], $p=$ 0.045 ) as previously described [30], while there was no effect of IA-2Ab or IAA. However, when infections during pregnancy were reported, both GAD65Ab $(\mathrm{OR}=0.35[95 \%$ CI $0.19-0.68], p=0.002)$ and IAA $(\mathrm{OR}=0.21[95 \% \mathrm{CI}$ $0.06-0.80], p=0.02$ ) were significantly associated with decreased risk of $\mathrm{HrBW}$, as well as several autoantibodies (GAD65Ab, IA-2Ab and IAA) (OR $=0.34$ [95\% CI 0.19 0.59 ], $p=0.0002$ ) (Table 2). There was no association between islet autoantibodies and HrBW in children of mothers without reported infections.

Are type 1 diabetes-risk HLA genotypes and infections during pregnancy related to $r B W$ ? No difference was found in the frequencies of infection with different HLA genotypes. In children born with HLA-DQ2/8 and without cord blood autoantibodies, there was a linear trend with
Table 1 Characteristics of newborns and mothers

\begin{tabular}{|c|c|c|c|c|}
\hline \multirow[t]{2}{*}{ Factor } & \multicolumn{3}{|c|}{$\begin{array}{l}\text { Fever or gastroenteritis-related infection } \\
\text { reported by mother during pregnancy }\end{array}$} & \multirow[t]{2}{*}{$p$ value $^{\mathrm{a}}$} \\
\hline & $\begin{array}{l}\text { No } \\
(n=16,908)\end{array}$ & $\begin{array}{l}\text { Yes, in one } \\
\text { trimester } \\
\text { only } \\
(n=2,509)\end{array}$ & $\begin{array}{l}\text { Yes, across } \\
\text { several } \\
\text { trimesters } \\
(n=339)\end{array}$ & \\
\hline \multicolumn{5}{|c|}{ Characteristics of newborn } \\
\hline \multicolumn{5}{|c|}{ Sex } \\
\hline Boy & 51.8 & 51.6 & 48.1 & \\
\hline Girl & 48.2 & 48.4 & 51.9 & 0.40 \\
\hline \multicolumn{5}{|c|}{ Standard BW } \\
\hline LrBW & 25.4 & 22.4 & 23.6 & \\
\hline Q1-Q3 & 50.0 & 50.7 & 44.8 & \\
\hline HrBW & 24.6 & 26.9 & 31.6 & 0.0003 \\
\hline \multicolumn{5}{|c|}{ Good health after delivery } \\
\hline Yes & 95.1 & 94.2 & 94.1 & \\
\hline No & 4.9 & 5.8 & 5.9 & 0.12 \\
\hline \multicolumn{5}{|c|}{ Cord blood autoantibodies } \\
\hline Yes & 4.0 & 3.7 & 5.6 & \\
\hline No & 96.0 & 96.3 & 94.4 & 0.24 \\
\hline \multicolumn{5}{|l|}{ Jaundice } \\
\hline Yes & 1.9 & 2.0 & 1.5 & \\
\hline No & 98.1 & 98.0 & 98.5 & 0.69 \\
\hline \multicolumn{5}{|l|}{ Siblings } \\
\hline Yes & 47.2 & 62.5 & 71.9 & \\
\hline No & 52.8 & 37.5 & 28.1 & $<0.0001$ \\
\hline \multicolumn{5}{|c|}{ Characteristics of mother } \\
\hline \multicolumn{5}{|c|}{ Age of mother (years) } \\
\hline$\leq 30$ & 49.2 & 44.0 & 42.2 & \\
\hline$>30$ & 50.8 & 56.0 & 57.8 & $<0.0001$ \\
\hline \multicolumn{5}{|l|}{ Smoker } \\
\hline Yes & 9.8 & 8.2 & 7.4 & \\
\hline No & 90.2 & 91.8 & 92.6 & 0.02 \\
\hline \multicolumn{5}{|c|}{ Mother's education } \\
\hline Primary & 5.9 & 4.7 & 5.0 & \\
\hline Secondary & 51.5 & 41.9 & 43.5 & \\
\hline College & 42.6 & 53.4 & 51.5 & $<0.0001$ \\
\hline \multicolumn{5}{|c|}{ Weight gain during pregnancy $(\mathrm{kg})$} \\
\hline$<5$ & 3.3 & 3.1 & 4.2 & \\
\hline $5-10$ & 17.4 & 19.1 & 16.2 & \\
\hline $11-15$ & 40.4 & 39.4 & 40.1 & \\
\hline$>15$ & 38.9 & 38.5 & 39.5 & 0.48 \\
\hline \multicolumn{5}{|c|}{ Lengthy or serious disease in the last 5 years } \\
\hline Yes & 11.4 & 14.0 & 19.2 & \\
\hline No & 88.6 & 86.0 & 80.8 & $<0.0001$ \\
\hline
\end{tabular}

Values are percentages

Q1-Q3, interquartile range

${ }^{\mathrm{a}} p$ value for heterogeneity

increasing frequency of children with HrBW among mothers reporting more infections $(p=0.007)$ (Table 3 ).

When adjusting for confounding factors by multiple regression analysis, the significant association observed 
Table 2 Association between cord blood autoantibodies and HrBW in children whose mothers did or did not report infections with fever or gastroenteritis during pregnancy

\begin{tabular}{|c|c|c|c|c|c|c|}
\hline \multirow[t]{3}{*}{ Autoantibodies } & \multicolumn{6}{|c|}{ Reported infections with fever or gastroenteritis during pregnancy } \\
\hline & \multicolumn{3}{|l|}{ No } & \multicolumn{3}{|l|}{ Yes } \\
\hline & $n$ (\% with $\mathrm{HrBW})$ & OR $(95 \% \mathrm{CI})$ & $p$ value & $n(\%$ with $\mathrm{HrBW})$ & OR $(95 \% \mathrm{CI})$ & $p$ value \\
\hline \multicolumn{7}{|l|}{ GAD65Ab } \\
\hline No & $16,407(24.6)$ & & & $2,765(28.0)$ & & \\
\hline Yes & $499(23.0)$ & $0.92(0.74-1.13)$ & 0.40 & $83(12.1)$ & $0.35(0.19-0.68)$ & 0.002 \\
\hline \multicolumn{7}{|l|}{ IA- $2 \mathrm{Ab}$} \\
\hline No & $16,846(24.6)$ & & & $2,836(27.5)$ & & \\
\hline Yes & $60(20.0)$ & $0.77(0.41-1.44)$ & 0.41 & $12(16.7)$ & $0.53(0.12-2.38)$ & 0.40 \\
\hline \multicolumn{7}{|l|}{ IAA } \\
\hline No & $16,595(24.6)$ & & & 2,794 (27.6) & & \\
\hline Yes & $168(27.4)$ & $1.15(0.82-1.62)$ & 0.41 & $27(7.4)$ & $0.21(0.06-0.80)$ & 0.02 \\
\hline \multicolumn{7}{|c|}{ GAD $65 \mathrm{Ab}, \mathrm{IAA}$ or IA- $2 \mathrm{Ab}$} \\
\hline No & $16,235(24.6)$ & & & $2,736(28.1)$ & & \\
\hline Yes & $673(24.1)$ & $0.97(0.81-1.16)$ & 0.73 & $112(11.6)$ & $0.34(0.19-0.59)$ & 0.0002 \\
\hline
\end{tabular}

$O R$, odds of having HrBW when autoantibody(s) present compared with odds of having HrBW when autoantibody(s) not present

between HrBW, HLA and infections was confirmed, and the negative association between $\mathrm{HrBW}$ and islet autoantibodies in the presence of infection remained pronounced (Table 4).

In addition, the association between $H L A-D Q 2 / 8$ and HrBW was aggravated when mothers reported infections in more than one trimester (Table 4) (interaction between HLA, HrBW and infections; $p=0.022$ ). Nevertheless, although the association between HLA and HrBW when infections were reported in more than one trimester was strongly positive ( $\mathrm{OR}=5.24$ [95\% CI 1.75-15.7], $p=0.003)$, there was still a weak but significant association when no infections were reported (1.22 [95\% CI 1.01-1.48], $p=$ 0.04). Thus, infections with fever, gastroenteritis, or both, during pregnancy influenced, but did not explain all, the association between $H L A-D Q 2 / 8$ and HrBW (Table 4). The non-diabetes risk-related $D Q B 1 * 0603$ was also associated with HrBW $(p=0.02)$, but only when several infections were reported (Table 4).

\section{Discussion}

In this study we further analysed our previously reported associations between HrBW and high-risk diabetes HLA genotypes, as well as islet autoantibodies, by testing the

Table 3 Percent of newborns with HrBW by different type 1 diabetes HLA risk groups and frequency of reported infections with fever or gastroenteritis during pregnancy

\begin{tabular}{|c|c|c|c|c|c|}
\hline \multirow[t]{2}{*}{ Diabetes risk } & \multirow[t]{2}{*}{ HLA-DQ } & \multicolumn{3}{|c|}{ Fever or gastoenteritis-related infections by the mother $(n=18,971)^{\mathrm{a}}$} & \multirow[t]{2}{*}{ Linear trend $p$ value } \\
\hline & & No & Yes, in one trimester only & Yes, across several trimesters & \\
\hline Very high & DQ2/8 & $582(27.8)$ & $90(31.1)$ & $19(63.2)$ & 0.007 \\
\hline High & $\mathrm{DQ} 8 / 8,8 / \mathrm{X}$ & $1,555(24.4)$ & $214(30.8)$ & $25(28.0)$ & 0.06 \\
\hline Moderate & $\mathrm{DQ} 2 / 2,2 / \mathrm{X}$ & $1,387(24.4)$ & $191(27.8)$ & $36(27.8)$ & 0.30 \\
\hline Neutral & Other & $2,431(24.7)$ & $395(26.3)$ & $52(26.9)$ & 0.44 \\
\hline Low $^{\mathrm{c}}$ & $D Q B I^{*} 0301$ & $3,766(24.0)$ & $584(25.7)$ & $55(29.1)$ & 0.23 \\
\hline Very low ${ }^{\mathrm{d}}$ & $D Q B I^{*} 0603$ & $2,545(26.0)$ & $364(28.0)$ & $53(41.5)$ & 0.03 \\
\hline No risk ${ }^{\mathrm{e}}$ & $D Q B I^{*} 0602$ & $3,969(24.0)$ & $578(28.0)$ & $80(30.0)$ & 0.02 \\
\hline
\end{tabular}

Values are $n(\%$ with $\mathrm{HrBW})$

$\mathrm{DQ} 8=D Q B 1 * 0302, \mathrm{DQ} 2=D Q A 1 * 0501-D Q B 1 * 0201, \mathrm{DQX}=$ not $D Q B 1 * 0201,0301,0302,0602,0603$

${ }^{a}$ All children with no cord blood autoantibodies

${ }^{\mathrm{b}}$ Test of linear trend in per cent of newborns with $\mathrm{HrBW}$

${ }^{\mathrm{c}}$ Not including $D Q B 1^{*} 0602 / 0301$ and $603 / 0301$

d Including $D Q B 1^{*} 0602 / 0604$ due to shared probe $D Q B 1 * 0602 / 3 / 4$

${ }^{\mathrm{e}}$ Not including $D Q B 1^{*} 0602 / 0603$ 
Table 4 Adjusted ORs of type 1 diabetes HLA risk genotypes on HrBW when mothers reported no infection with fever or gastroenteritis, infection with fever and/or gastroenteritis in one trimester only or infections with fever and/or gastroenteritis in more than one trimester

\begin{tabular}{|c|c|c|c|c|c|c|}
\hline & \multicolumn{6}{|c|}{ Fever or gastroenteritis-related infection reported during pregnancy } \\
\hline & \multicolumn{2}{|l|}{ No } & \multicolumn{2}{|l|}{ One trimester only } & \multicolumn{2}{|c|}{ In more than one trimester } \\
\hline & OR $(95 \% \mathrm{CI})$ & $p$ value & OR $(95 \% \mathrm{CI})$ & $p$ value & OR $(95 \% \mathrm{CI})$ & $p$ value \\
\hline \multicolumn{7}{|c|}{ HLA risk group } \\
\hline $\mathrm{DQ} 2 / 8$ & $1.22(1.01-1.48)$ & 0.04 & $1.17(0.72-1.92)$ & 0.52 & $5.24(1.75-15.7)$ & 0.003 \\
\hline $\mathrm{DQ} 8 / 8,8 / \mathrm{X}$ & $0.97(0.85-1.11)$ & 0.66 & $1.23(0.88-1.72)$ & 0.22 & $1.18(0.42-3.34)$ & 0.75 \\
\hline$D Q B I^{*} 0603^{a}$ & $1.07(0.97-1.19)$ & 0.13 & $1.05(0.80-1.39)$ & 0.71 & $2.43(1.15-5.15)$ & 0.02 \\
\hline$D Q B I^{*} 0602^{a}$ & $0.95(0.86-1.04)$ & 0.24 & $1.03(0.81-1.30)$ & 0.83 & $1.20(0.62-2.30)$ & 0.59 \\
\hline \multicolumn{7}{|l|}{ Autoantibodies } \\
\hline Yes & $0.98(0.81-1.18)$ & 0.80 & $0.37(0.19-0.71)$ & 0.003 & $0.11(0.01-0.80)$ & 0.03 \\
\hline
\end{tabular}

For actual numbers of children, see Table 3

ORs were calculated using multiple logistic regression adjusted for sex, gestational age, presence of jaundice, whether newborn has a sibling and health of newborn, as well as working or smoking during pregnancy, age, education, lengthy or serious disease over the previous years and weight gain of mother

Reference group is all other HLA genotypes. DQ8 $=D Q B 1 * 0302, \mathrm{DQ} 2=D Q A 1 * 0501-D Q B 1 * 0201, \mathrm{DQX}=$ not $D Q B 1 * 0201,0301,0302,0602$, 0603

${ }^{\mathrm{a}}$ See Table 2 for details

hypothesis that infections during pregnancy may affect the rBW [30]. The major observation in the present investigation is that there was a significant, but complex interaction between $\mathrm{rBW}$ and infections and islet autoantibodies as well as HLA.

First, reported infections with fever, gastroenteritis, or both, increased the risk of HrBW. This finding supported our hypothesis that reported gestational infections in the general population of non-diabetic mothers might increase the risk of the child being born with HrBW. This type of association in humans has not, to the best of our knowledge, been reported before, although an adipogenic effect of adenovirus has been described [40].

Second, the significant decreased risk of $\mathrm{HrBW}$ in the presence of cord blood islet autoantibodies [30] was observed only when the mother reported fever, gastroenteritis, or both, during pregnancy. Thus, our previously reported reduced risk of $\mathrm{HrBW}$ in the presence of GAD65Ab may be explained by gestational infections. We therefore considered the possibility that infections during pregnancy would induce islet autoantibodies. However, our data did not reveal an increased incidence of positive cord blood autoantibodies in children born to mothers who reported gestational infections.

The third major finding was that reported infections during pregnancy aggravated, but did not explain all of the previously reported association between HLA and HrBW [30] (Table 4). The remarkable increase in the risk of $\mathrm{HrBW}$ in $H L A-D Q 2 / 8$-positive children born to mothers reporting infections is of considerable interest as more than $30 \%$ of children developing type 1 diabetes have this HLA genotype [41, 42].
Taken together, our major finding was that infections interact with HLA in modifying intrauterine growth, resulting in children with HrBW. This finding is supported by our observation that also the diabetes low-risk allele, $D Q B 1^{*} 0603$, had an increased risk of HrBW when fever, gastroenteritis, or both, was reported in more than one trimester. Thus, it cannot be excluded that infections during pregnancy may explain the previously reported increase in BW with the $D Q B 1^{*} 0603$-linked DR13 [43].

At present there is no simple explanation of the interaction between infections, HLA of the child and HrBW. Our speculation is that certain infectious agents are taken up by antigen-presenting cells in the mother, processed by these cells and then presented at the cell surface by HLA class heterodimeric proteins as part of the trimolecular complex. The peptides presented by HLA will be different for different HLA genotypes but may nevertheless induce a vigorous immune response when seen by the $\mathrm{T}$ cell receptors on CD4-positive $\mathrm{T}$ lymphocytes. The ensuing immune response is expected to induce a marked production in cytokines, resulting in fever and metabolic changes. It is, for example, possible to speculate that the well-known insulin resistance during infection may lead to hyperinsulinaemia, resulting in an increased growth of the fetus. Alternatively, transient hyperglycaemia associated with insulin resistance might also affect fetal growth. While metabolic responses in the mother are likely to influence the growth of the fetus, other explanations of the interaction between infections, HLA and HrBW may include a direct effect of the infectious agent on the fetus.

In the present study, we HLA typed the child, not the mother, but at least one of the HLA heterodimers of the 
fetus will be shared with the mother. It is therefore possible that the effect of an infection is aggravated if the mother and the child share an HLA genotype that is associated with a vigorous immune response to a certain infectious agent. Further studies will be needed to dissect these intricate but potentially important interactions between infections and fetal growth.

The present study is a unique population-based cohort of newborn children representing 35,683/48,058 newborns during 4 years of ascertainment. Although it was not possible to obtain complete questionnaires from all the parents to be filled out when the child was 2 months of age, our previous analyses indicate that there was little bias in missing data [30, 33]. Since the study design was population-based in a defined geographical area and since the mothers answered the questionnaires without any information about HLA risk of the child or cord blood autoantibodies, the risk of recall bias was minimised. This study therefore allowed us to examine differences in $\mathrm{rBW}$, to reveal relationships between $\mathrm{rBW}$ and reported infections, and HLA as well as cord blood autoantibodies. When excluding children born to diabetic mothers, preterm babies and twins or triplets, we removed potential confounders without reducing statistical power.

The questionnaire response rate of $67 \%$ might have given some bias to different subgroups as those displayed in ESM Table 1. Although our results reveal that infections affect $\mathrm{rBW}$, it is important to note that HLA genotypes are influencing intrauterine growth also in the absence of reported infections. This observation may be a result of under-reporting of infections due to the fact that mothers do not recall minor infectious events, especially if they occurred early in pregnancy. The optimal solution to this problem would have been blood sampling during pregnancy, but this could not be done in this study. The frequency of reported gastroenteritis was low in our study $(6.7 \%)$ compared with a recent study $(30 \%)$, where no relationship was seen between BW and gastroenteritis [44]. However, the author did report a small increase in preterm labour in women with gastroenteritis in months 4,5 and 7 of pregnancy [44]. The difference in frequencies of gastroenteritis between these two studies may be due to imprecise reporting of infections. Another possible explanation could be that our question to the mothers was distinctly focused on infectious gastroenteritis and fever, and did not include chronic diarrhoea or nausea during early pregnancy (ESM: Questionnaire, Question 1). Further studies will be needed to clarify frequencies and type of infections in relation to rBW and the HLA of both the mother and the child.

BW in the general Swedish population of newborns is increasing, especially the incidence of children with a high BW and those large for gestational age [45]. BW corrected for gestational age, $\mathrm{rBW}$, is an outcome of intrauterine growth rate, which is influenced by multiple factors such as intrauterine infections, cord blood flow, maternal disease, drugs and maternal weight gain [46, 47] as well as the HLA type of the child [30]. High BW and increased growth in infancy have been reported as risk factors for type 1 diabetes [9-11]. This phenomenon is not understood. Prior studies by others have not examined relationships between rBW and HLA as well as islet autoantibodies in the newborn child. Our data suggest that the interaction between HLA, islet autoantibodies and rBW is complex. We interpret the data in Table 4 to indicate that islet autoantibodies in the cord blood of children of mothers reporting infections reduced the $\mathrm{BBW}$ regardless of the HLA of the child. Although we do not know the HLA type of the mother we would anticipate that she may carry at least one allele that is diabetes high-risk, which in turn is associated with islet autoantibodies also in the healthy population [41]. It is therefore possible that the reduced risk of $\mathrm{HrBW}$ is due to the possibility that islet autoimmunity was already present in some mothers reporting infections. The immune response to infections may be affected in islet autoantibodypositive mothers in a way that fetal growth is reduced rather than accelerated by a gestational infection.

Thus, the previously reported association between high BW and risk of type 1 diabetes [9], may be explained by the interaction between infections and diabetes high-risk HLA affecting intrauterine growth. This is, to the best of our knowledge, a novel finding and may be important for the understanding of type 1 diabetes aetiology.

In conclusion, our reported [30] association between diabetes high-risk HLA and HrBW may be explained by infections during pregnancy. The aggravating effect on HrBW by infections also on $H L A-D Q B 1^{*} 0603$ (DR13) is underscoring the importance of HLA. While mothers reporting infections had no increased risk to give birth to a child with cord blood islet autoantibodies, their islet autoimmunity was associated with a reduced risk of HrBW. Gestational islet autoimmunity could therefore possibly explain the observation that children born with islet autoantibodies have a reduced risk of developing autoantibodies against GAD65, IA-2 or insulin later in life [29]. As reported infections affected $\mathrm{rBW}$ in association with HLA, it will be necessary in future studies to determine the nature of such infections and carefully document the infectious agents. The children affected by intrauterine infections may have an altered infant growth rate, which may be important for type 1 diabetes risk [48-50]. The DiPiS study is longitudinal and children in this report are followed for the development of islet autoimmunity and type 1 diabetes as well as growth. These future analyses may allow us to establish whether the complex interaction between $\mathrm{rBW}$ and infections, and HLA as well as islet autoantibodies is increasing the risk of type 1 diabetes. 
Acknowledgements Co-authors in the DiPiS study group are: $\mathrm{P}$. Almgren, B. Buveris-Svendburg, A. Carlsson, E. Cederwall, C. Cilio, J. Gerardsson, B. Jönsson, K. Kockum, K. Larsson, B. Lindberg, J. Neiderud, A. Nilsson, M. Pelkonen, H. Rastkhani and S. Sjöblad. We thank all the participating parents and children in DiPiS. Our research is supported in part by the Swedish Research Council (Grant 14064), Juvenile Diabetes Research Foundation, Wallenberg Foundation, Swedish Childhood Diabetes Foundation, Swedish Diabetes Association, Nordisk Insulin Fund, National Institutes of Health (DK26190), UMAS funds, Terry \& Louise Gregg Diabetes in Pregnancy Award from the American Diabetes Association, Lion Club International, District 101-S and the Skåne County Council Foundation for Research and Development.

Duality of interest There is no duality of interest

\section{References}

1. Green A, Patterson CC on behalf of the EURODIAB TIGER Study Group (2001) Trends in the incidence of childhood-onset diabetes in Europe 1989-1998. Diabetologia 44(Suppl 3):B3-B8

2. DIAMOND Project Group (2006) Incidence and trends of childhood type 1 diabetes worldwide 1990-1999. Diabet Med 23:857-866

3. Dahlquist G, Mustonen L (1994) Childhood onset diabetes-time trends and climatological factors. Int J Epidemiol 23:1234-1241

4. Gardner SG, Bingley PJ, Sawtell PA, Weeks S, Gale EA (1997) Rising incidence of insulin dependent diabetes in children aged under 5 years in the Oxford region: time trend analysis. The Bart's-Oxford Study Group. BMJ 315:713-717

5. Karvonen M, Pitkaniemi J, Tuomilehto J (1999) The onset age of type 1 diabetes in Finnish children has become younger. The Finnish Childhood Diabetes Registry Group. Diabetes Care 22:1066-1070

6. Redondo MJ, Fain PR, Eisenbarth GS (2001) Genetics of type 1A diabetes. Recent Prog Horm Res 56:69-89

7. Barnett AH, Eff C, Leslie RD, Pyke DA (1981) Diabetes in identical twins. A study of 200 pairs. Diabetologia 20:87-93

8. Kaprio J, Tuomilehto J, Koskenvuo M et al (1992) Concordance for type 1 (insulin-dependent) and type 2 (non-insulin-dependent) diabetes mellitus in a population-based cohort of twins in Finland. Diabetologia 35:1060-1067

9. Dahlquist G, Bennich SS, Kallen B (1996) Intrauterine growth pattern and risk of childhood onset insulin dependent (type I) diabetes: population based case-control study. BMJ 313:11741177

10. Stene LC, Magnus P, Lie RT, Sovik O, Joner G (2001) Birth weight and childhood onset type 1 diabetes: population based cohort study. BMJ 322:889-892

11. Cardwell CR, Carson DJ, Patterson CC (2005) Parental age at delivery, birth order, birth weight and gestational age are associated with the risk of childhood type 1 diabetes: a UK regional retrospective cohort study. Diabet Med 22:200-206

12. Levy-Marchal C, Jaquet D (2004) Long-term metabolic consequences of being born small for gestational age. Pediatr Diabetes 5:147-153

13. Veening MA, Van Weissenbruch MM, Delemarre-Van De Waal HA (2002) Glucose tolerance, insulin sensitivity, and insulin secretion in children born small for gestational age. J Clin Endocrinol Metab 87:4657-4661

14. Dahlquist G, Frisk G, Ivarsson SA, Svanberg L, Forsgren M, Diderholm H (1995) Indications that maternal Coxsackie B virus infection during pregnancy is a risk factor for childhood-onset IDDM. Diabetologia 38:1371-1373

15. Dahlquist GG, Ivarsson S, Lindberg B, Forsgren M (1995) Maternal enteroviral infection during pregnancy as a risk factor for childhood IDDM. A population-based case-control study. Diabetes 44:408-413

16. Hyoty H, Hiltunen M, Knip M et al (1995) A prospective study of the role of Coxsackie $\mathrm{B}$ and other enterovirus infections in the pathogenesis of IDDM. Childhood Diabetes in Finland (DiMe) Study Group. Diabetes 44:652-657

17. Viskari HR, Roivainen M, Reunanen A et al (2002) Maternal firsttrimester enterovirus infection and future risk of type 1 diabetes in the exposed fetus. Diabetes 51:2568-2571

18. Forrest JM, Menser MA, Burgess JA (1971) High frequency of diabetes mellitus in young adults with congenital rubella. Lancet 2:332-334

19. Menser MA, Forrest JM, Bransby RD (1978) Rubella infection and diabetes mellitus. Lancet 1:57-60

20. Ray CG, Palmer JP, Crossley JR, Williams RH (1980) Coxsackie $\mathrm{B}$ virus antibody responses in juvenile-onset diabetes mellitus. Clin Endocrinol (Oxf) 12:375-378

21. Banatvala JE, Bryant J, Schernthaner G et al (1985) Coxsackie B, mumps, rubella, and cytomegalovirus specific IgM responses in patients with juvenile-onset insulin-dependent diabetes mellitus in Britain, Austria, and Australia. Lancet 1:1409-1412

22. Hyoty H, Taylor KW (2002) The role of viruses in human diabetes. Diabetologia 45:1353-1361

23. Green J, Casabonne D, Newton R (2004) Coxsackie B virus serology and type 1 diabetes mellitus: a systematic review of published case-control studies. Diabet Med 21:507-514

24. Baekkeskov S, Aanstoot HJ, Christgau S et al (1990) Identification of the $64 \mathrm{~K}$ autoantigen in insulin-dependent diabetes as the GABA-synthesizing enzyme glutamic acid decarboxylase. Nature 347:151-156

25. Solimena M, Dirkx R Jr, Hermel JM et al (1996) ICA 512, an autoantigen of type I diabetes, is an intrinsic membrane protein of neurosecretory granules. EMBO J 15:2102-2114

26. Saeki K, Zhu M, Kubosaki A, Xie J, Lan MS, Notkins AL (2002) Targeted disruption of the protein tyrosine phosphatase-like molecule IA-2 results in alterations in glucose tolerance tests and insulin secretion. Diabetes 51:1842-1850

27. Atkinson MA, Eisenbarth GS (2001) Type 1 diabetes: new perspectives on disease pathogenesis and treatment. Lancet 358:221-229

28. Lindberg B, Ivarsson SA, Landin-Olsson M, Sundkvist G, Svanberg L, Lernmark A (1999) Islet autoantibodies in cord blood from children who developed type I (insulin-dependent) diabetes mellitus before 15 years of age. Diabetologia 42:181-187

29. Koczwara K, Bonifacio E, Ziegler AG (2004) Transmission of maternal islet antibodies and risk of autoimmune diabetes in offspring of mothers with type 1 diabetes. Diabetes 53:1-4

30. Larsson HE, Lynch K, Lernmark B et al (2005) Diabetesassociated HLA genotypes affect birthweight in the general population. Diabetologia 48:1484-1491

31. Hummel M, Marienffeld S, Huppmann M et al (2006) Interaction between maternal type 1 diabetes and HLA DR4 increases fetal growth. Diabetologia 49(Suppl 1):68

32. Larsson K, Elding-Larsson H, Cederwall E et al (2004) Genetic and perinatal factors as risk for childhood type 1 diabetes. Diabetes Metab Res Rev 20:429-437

33. Lernmark B, Elding-Larsson H, Hansson G, Lindberg B, Lynch K, Sjoblad S (2004) Parent responses to participation in genetic screening for diabetes risk. Pediatr Diabetes 5:174-181

34. Ilonen J, Reijonen H, Herva E et al (1996) Rapid HLA-DQB1 genotyping for four alleles in the assessment of risk for IDDM in 
the Finnish population. The Childhood Diabetes in Finland (DiMe) Study Group. Diabetes Care 19:795-800

35. Sjoroos M, Iitia A, Ilonen J, Reijonen H, Lovgren T (1995) Triple-label hybridization assay for type-1 diabetes-related HLA alleles. Biotechniques 18:870-877

36. Hampe CS, Hammerle LP, Bekris L et al (2000) Recognition of glutamic acid decarboxylase (GAD) by autoantibodies from different GAD antibody-positive phenotypes. J Clin Endocrinol Metab 85:4671-4679

37. Grubin CE, Daniels T, Toivola B et al (1994) A novel radioligand binding assay to determine diagnostic accuracy of isoformspecific glutamic acid decarboxylase antibodies in childhood IDDM. Diabetologia 37:344-350

38. Verge CF, Stenger D, Bonifacio E et al (1998) Combined use of autoantibodies (IA-2 autoantibody, GAD autoantibody, insulin autoantibody, cytoplasmic islet cell antibodies) in type 1 diabetes: combinatorial islet autoantibody workshop. Diabetes 47:1857-1866

39. Williams AJ, Bingley PJ, Bonifacio E, Palmer JP, Gale EA (1997) A novel micro-assay for insulin autoantibodies. J Autoimmun 10:473-478

40. Atkinson RL, Dhurandhar NV, Allison DB et al (2005) Human adenovirus-36 is associated with increased body weight and paradoxical reduction of serum lipids. Int $\mathrm{J}$ Obes (Lond) 29:281-286

41. Graham J, Hagopian WA, Kockum I et al (2002) Genetic effects on age-dependent onset and islet cell autoantibody markers in type 1 diabetes. Diabetes 51:1346-1355

42. Lambert AP, Gillespie KM, Thomson G et al (2004) Absolute risk of childhood-onset type 1 diabetes defined by human leukocyte antigen class II genotype: a population-based study in the United Kingdom. J Clin Endocrinol Metab 89:4037-4043

43. Aroviita P, Partanen J, Sistonen P, Teramo K, Kekomaki R (2004) High birth weight is associated with human leukocyte antigen (HLA) DRB1*13 in full-term infants. Eur J Immunogenet 31:21-26

44. Ludvigsson JF (2001) Effect of gastroenteritis during pregnancy on neonatal outcome. Eur J Clin Microbiol Infect Dis 20: 843-849

45. National Board of Health and Welfare (2002) Fakta om mammor, förlossningar, nyfödda barn-medicinska födelseregistret 19732000. Medical birth registry

46. Brooke OG, Anderson HR, Bland JM, Peacock JL, Stewart CM (1989) Effects on birth weight of smoking, alcohol, caffeine, socioeconomic factors, and psychosocial stress. BMJ 298:795-801

47. Hutcheon JA, Platt RW, Meltzer SJ, Egeland GM (2006) Is birth weight modified during pregnancy? Using sibling differences to understand the impact of blood glucose, obesity, and maternal weight gain in gestational diabetes. Am J Obstet Gynecol 195:488-494

48. Blom L, Persson LA, Dahlquist G (1992) A high linear growth is associated with an increased risk of childhood diabetes mellitus. Diabetologia 35:528-533

49. EURODIAB Substudy 2 Study Group (2002) Rapid early growth is associated with increased risk of childhood type 1 diabetes in various European populations. Diabetes Care 25:1755-1760

50. Hypponen E, Virtanen SM, Kenward MG, Knip M, Akerblom HK (2000) Obesity, increased linear growth, and risk of type 1 diabetes in children. Diabetes Care 23:1755-1760 